Short Note

\title{
The Marginal Value of Heat in the Korean Manufacturing Industry
}

\author{
Hyo-Jin Kim, Hee-Hoon Kim and Seung-Hoon Yoo * \\ Department of Energy Policy, Graduate School of Energy \& Environment, Seoul National University of Science \\ \& Technology, 232 Gongreung-Ro, Nowon-Gu, Seoul 01811, Korea; hjinkim@seoultech.ac.kr (H.-J.K.); \\ hhoonkim@seoultech.ac.kr (H.-H.K.) \\ * Correspondence: shyoo@seoultech.ac.kr
}

Received: 30 March 2018; Accepted: 19 May 2018; Published: 1 June 2018

\begin{abstract}
Thirty industrial heat (IH) providers in Korea have better energy efficiency and emit lower air pollutants than individual companies that produce and consume heat for their industrial production. Because these providers collect waste heat from garbage incineration plants, power plants, or industrial processes of steel and chemical companies, as well as heat generated through combined heat and power plants and boilers. IH is an important input, used in industrial production as a form of hot water or steam. This note tries to assess the marginal value (MV) of IH in the manufacturing industry, using the specific case of Korea. To this end, a trans-log production function is estimated using the data gathered from a survey of 256 manufacturing firms in Korea. The MV of IH is estimated to be KRW 203,696 (USD 175.40) per tonne. This estimate is statistically significant at the $1 \%$ level. The average price of $\mathrm{IH}$, defined as total expenditure on IH purchased in 2016 divided by total amount of IH purchased in 2016, is KRW 39,455 (USD 34.00) per tonne. Therefore, the MV of $\mathrm{IH}$ is about five times as large as the average price of $\mathrm{IH}$.
\end{abstract}

Keywords: industrial heat; industrial production; marginal value; trans-log production function

\section{Introduction}

In Korea, thirty industrial heat $(\mathrm{IH})$ providers use boilers or combined heat and power (CHP) plants to produce IH. Moreover, the providers collect waste heat from garbage incineration plants or industrial processes of steel and chemical companies, to supply IH to consumers demanding IH [1]. Thus, the professional providers show better performance in energy efficiency and air pollutant emissions reduction than individual companies that produce and consume heat for their own industrial production [2-4]. For example, as of 2016, the amount of IH supplied for consumers by the providers was $64,713,000 \mathrm{Gcal}$. The IH sources were boilers $(45,401,000 \mathrm{Gcal}$, or $70.2 \%)$, CHP plants $(12,038,324$ Gcal, or $18.6 \%$ ), waste heat from garbage incineration plants, power plants, and industrial process of steel and chemical companies $(3,981,562 \mathrm{Gcal}$, or $6.2 \%)$, and fuel cell, heat pump, and solar heat $(3,291,569 \mathrm{Gcal}$, or $5.1 \%)$ [5].

There are three approaches found in the literature that can be used to measure the economic value of IH. The first is to collect data on IH consumption, IH price, and factors affecting IH consumption; estimate the demand function for IH using the data; and then calculate the MV of IH using the demand function [6]. The second approach is to estimate the cost function for the IH-utilizing firms, derive the demand function employing microeconomic theory, and then compute the MV of IH by employing the demand function [7]. The third approach is to estimate the production function for the IH-utilizing firms, derive the demand function adopting microeconomic theory, and then compute the MV of IH by adopting the demand function [8-11]. The demand for IH means the demand for an intermediate good, rather than the demand for a final good. Thus, in the economic sense, the demand for $\mathrm{IH}$ 
indicates derived demand. In this regard, the second and the third approaches may be better than the first approach. Usually, the third approach is easier to apply and more frequently found in the literature than the second. Moreover, accordingly to microeconomics, the third approach is dual to the second one. This implies that researchers can obtain similar results by applying either approach. Thus, this study seeks to employ the third approach.

Usually, the production inputs playing the role of independent variables in the production function are capital, labor, and intermediate. Each input contributes to the production of a good or a service and the creation of value-added. IH can also be an important input used in industrial production in the form of hot water or steam [12]. This paper has a particular interest in analyzing the role of $\mathrm{IH}$ as a production input. Thus, it attempts to assess the marginal value (MV) of IH in the Korean manufacturing industry. Following a practice of prior, related studies dealing with water [10,11], electricity [9], and natural gas [8], this study employs a trans-log production function and implements some specification tests for the function.

The data were gathered from a survey of 256 manufacturing firms in Korea. The production inputs considered here are capital, labor, intermediate, and IH. More specifically, the marginal contribution of IH to the value-added of Korean manufacturing firms will be derived. Information on the MV of IH is useful in various aspects. For example, MV is utilized in the economic evaluation of new projects regarding IH supply and the appropriate allocation of heat among heat-using purposes and industrial sectors.

To the best of authors' knowledge, this study is the first trial of assessing the MV of IH in the literature. Thus, the message will be useful, and the results from this study will provide interesting insights for IH supply management. The rest of the paper consists of three sections. The model adopted for this study is presented in the next section. The data used and the results are explained in the third section. Conclusions are offered in the final section.

\section{Model}

Let $Y, K, L, M$, and $H$ be the output, capital input, labor input, intermediate input, and IH input, respectively. The production function can be specified as $Y=f(K, L, M, H)$. The MV of IH is defined as $\partial Y / \partial H$. A simple Cobb-Douglas production function is widely used in the literature. However, this paper applies the trans-log production function suggested by Christensen et al. [13]. This is because the trans-log production function can reflect a wider range of substitution of transformation patterns. Moreover, the trans-log production function includes the Cobb-Douglas production function as a special case, and thus a specification test of the first versus the second can be easily performed.

The trans-log production function where inputs are capital, labor, intermediate, and $\mathrm{IH}$ is formulated as:

$$
\begin{aligned}
\ln Y= & \beta_{0}+\beta_{1} \ln K+\beta_{2} \ln L+\beta_{3} \ln M+\beta_{4} \ln H+\beta_{5} \ln K \ln L \\
& +\beta_{6} \ln K \ln M+\beta_{7} \ln K \ln H+\beta_{8} \ln L \ln M+\beta_{9} \ln L \ln H \\
& +\beta_{10} \ln M \ln H+\beta_{11}(\ln K)^{2}+\beta_{12}(\ln L)^{2}+\beta_{13}(\ln M)^{2} \\
& +\beta_{14}(\ln H)^{2}
\end{aligned}
$$

where $\beta$ represents the parameters to be estimated.

After taking the partial differentiation of Equation (1) and arranging it, the MV of heat can be easily derived as:

$$
\frac{\partial Y}{\partial H}=\left(\beta_{4}+\beta_{7} \ln K+\beta_{9} \ln L+\beta_{10} \ln M+2 \beta_{14} \ln H\right) \frac{Y}{H}
$$

In order to obtain a point estimate of $\mathrm{MV}$ for heat, $M V_{H}$, we should know the values for $Y, K, L$, $M$, and $H$. For this purpose, this note uses their sample averages. Therefore, $M V_{H}$ can be estimated as:

$$
M V_{H}=\left(\hat{\beta}_{4}+\hat{\beta}_{7} \ln \bar{K}+\hat{\beta}_{9} \ln \bar{L}+\hat{\beta}_{10} \ln \bar{M}+2 \hat{\beta}_{14} \ln \bar{H}\right) \frac{\bar{Y}}{\bar{H}}
$$


where $\hat{\beta}_{4}, \hat{\beta}_{7}, \hat{\beta}_{9}, \hat{\beta}_{10}$, and $\hat{\beta}_{14}$ are the estimates for $\beta_{4}, \beta_{7}, \beta_{9}, \beta_{10}$, and $\beta_{14}$, respectively, and $\bar{Y}, \bar{K}, \bar{L}, \bar{M}$, and $\bar{H}$ are the sample averages for $Y, K, L, M$, and $H$, respectively.

\section{Results}

To estimate the marginal value of IH use, micro data on the heat use of individual companies are required. The authors conducted extensive investigations into whether such data were available, but they could not find the appropriate data. Thus, they decided to implement a survey of manufacturing firms directly, during June and July 2017. One complication in doing so is that it is quite expensive to administer such a survey in Korea. The authors were able to secure a budget to investigate about 1148 manufacturing companies. Of them, 256 firms reported that they consumed $\mathrm{IH}$ as a production input. For this reason, the final number of observations used in this study is 256 . This means that $22.3 \%$ of the sampled firms consumed IH for industrial production in 2016 . Some variables utilized in this paper are explained in Table 1 . However, the authors think that appropriate sample size should be at least 1000, since Korea's Ministry of Strategy and Finance recommended the use of 1000 observations for policy analysis. As the second stage of this study, more observations should be added to the analysis in the near future.

One more point needs to be addressed. In the questionnaire, the authors asked questions about IH usage, production amount, sales amount, labor input, capital input, and intermediate input from 2014 to 2016. However, some companies were founded in 2016. Moreover, other companies could not report some necessary information prior to 2016. Therefore, in order to maintain the consistency of time in analyzing the data of 256 companies, the authors utilized the data on $\mathrm{IH}$ consumption only for the year 2016.

Table 1. Description of the variables used in this study.

\begin{tabular}{cccc}
\hline Variables & Definitions & Mean & Standard Deviation \\
\hline$Y$ & Value added in 2016 (unit: million KRW) & 7535.58 & $33,750.92$ \\
$K$ & Capital stock in 2016 (unit: million KRW) & $13,705.60$ & $73,622.07$ \\
$L$ & Labor used in 2016 (unit: persons) & 61.29 & 145.91 \\
$M$ & Intermediate input in 2016 (unit: million KRW) & $20,626.98$ & $94,621.44$ \\
$H$ & Heat consumed in 2016 (unit: tonne) & 5557.92 & $30,809.43$ \\
\hline
\end{tabular}

Note: KRW 7535.58 million, KRW 13,705.60 million, and KRW 20,626.98 million are equal to USD 6.49 million, USD 11.80 million, and USD 17.76 million, respectively.

The results of estimating the trans-log production function of Equation (1) are presented in Table 2. The dependent variable used in this note, $\ln Y$, is the natural logarithm of value-added rather than the sales amount. This variable is measured over the entire year of 2016. $K, L, M$, and $H$ indicate capital stock in 2016 (unit: million KRW), labor used in 2016 (unit: persons), intermediate input in 2016 (unit: million KRW), and heat consumed in 2016 (unit: tonnes), respectively. The model explains about 83.1\% of the variability in the response variable.

Table 2. Estimation results of the trans-log production function

\begin{tabular}{ccc}
\hline Variables & Coefficient Estimates & $\boldsymbol{t}$-Values \\
\hline Constant & 18.9033 & $6.99 *$ \\
$\ln K$ & -0.7821 & -1.44 \\
$\ln L$ & 10.0421 & $8.54^{*}$ \\
$\ln M$ & -5.4825 & $-5.62^{*}$ \\
$\ln H$ & -1.4945 & $-4.57^{*}$ \\
$\ln K \ln L$ & 0.1479 & 0.87 \\
$\ln K \ln M$ & -0.1325 & -1.65 \\
$\ln K \ln H$ & 0.0477 & 0.85 \\
$\ln L \ln M$ & -1.7781 & $-6.75^{*}$ \\
\hline
\end{tabular}


Table 2. Cont.

\begin{tabular}{|c|c|c|}
\hline Variables & Coefficient Estimates & $t$-Values \\
\hline $\ln L \ln H$ & -0.5287 & $-6.13 *$ \\
\hline $\ln M \ln H$ & 0.2866 & $5.95 *$ \\
\hline$(\ln K)^{2}$ & 0.08413 & 1.22 \\
\hline$(\ln L)^{2}$ & 1.1809 & $5.17 *$ \\
\hline$(\ln M)^{2}$ & 0.6406 & $6.86 *$ \\
\hline$(\ln H)^{2}$ & 0.0302 & 1.64 \\
\hline R-squared & 0.831 & \\
\hline$F$-value ( $p$-value $)^{\text {a }}$ & $84.61(0.000)$ & \\
\hline Ramsey's RESET2 ( $p$-value) ${ }^{b}$ & $0.89(0.346)$ & \\
\hline Number of observations & 256 & \\
\hline Marginal value of heat per tonne & KRW 203,696 (USD 175.40) & $2.79 *$ \\
\hline
\end{tabular}

Note: The dependent variable is the natural logarithm of value-added created in 2016. $K, L, M$, and $H$ indicate capital stock in 2016 (unit: million KRW), labor used in 2016 (unit: persons), intermediate input in 2016 (unit: million KRW), and heat consumed in 2016 (unit: tonne), respectively. ${ }^{*}$ implies statistical significance at the $1 \%$ level. ${ }^{\text {a }}$ The null hypothesis is that all coefficients except for the constant term are zero. ${ }^{\mathrm{b}}$ Ramsey's RESET2 specification test is given in Ramsey [14], and the null hypothesis is that the model is correctly specified.

We performed three versions of the specification test to ascertain the appropriateness of the trans-log production function. First, the estimated equation was statistically significant at the $1 \%$ level, since the $F$-value computed under the null hypothesis that all coefficients except for the constant term are zero was 84.61 , and its corresponding $p$-value was 0.000 . Thus, the null hypothesis can be rejected, and the estimated equation is statistically significant at the $1 \%$ level. Second, we employed a general specification test for the linear regression given in Ramsey [14]. The test statistic calculated under the null hypothesis that the model is correctly specified was 0.89 , and its corresponding $p$-value was 0.346 . Thus, the null hypothesis cannot be rejected at the $1 \%$ level. Consequently, it can be found that the model does not suffer from mis-specification. Third, we did a specification test of the trans-log production function versus the Cobb-Douglas production function. The F-statistics computed under the null hypothesis that Cobb-Douglas production function is correctly specified and its corresponding $p$-value were 14.75 and 0.000 , respectively. Therefore, the null hypothesis could be rejected at the $1 \%$ level, and the trans-log production function performed better than the Cobb-Douglas production function. We could then proceed to assess the MV of IH with the estimation results of the trans-log production function.

Using Equation (3) and the sample means for the 256 observations, the MV of IH was estimated to be KRW 203,696 (USD 175.40) per tonne, as shown in the last row of Table 2. This estimate is statistically significant at the $1 \%$ level. The average price of $\mathrm{IH}$, defined as total expenditure on $\mathrm{IH}$ purchased in 2016 divided by the total amount of IH purchased in 2016, was KRW 39,455 (USD 34.00) per tonne. Interestingly, the MV of $\mathrm{IH}$ was about five times as large as the average price of $\mathrm{IH}$. The stable provision of $\mathrm{IH}$ to industrial production is quite important for the manufacturing industry, in that $\mathrm{IH}$ consumed in the manufacturing industry produces much more value than its price.

\section{Conclusions}

$\mathrm{IH}$ is an important input used in industrial production, in the form of hot water or steam. For the purpose of gathering micro data required in the assessment, a nationwide survey of 1148 firms was implemented, and of them 256 firms observed that they consume IH in the industrial production process. The trans-log production function that contains the four inputs of capital, labor, intermediate, and IH was estimated, and the MV of IH was computed to be KRW 203,696 (USD 175.40) per tonne. This value was statistically significant at the $1 \%$ level and about five times greater than the average price of IH (KRW 39,455 (USD 34.00) per tonne).

This note added a contribution to the existing literature by deriving the MV of IH in the Korean manufacturing industry. So far as the authors are aware, this study is the first trial to assess the 
MV of IH consumed in the manufacturing industry. The note provided empirical evidence that the production function approach, theoretically grounded in microeconomics, could be successfully utilized in assessing the MV of IH. The authors think that the framework of this note can provide important insights for IH supply management.

Concerning IH consumption, there are three stakeholders: IH-supplying industry; IH-utilizing industry; and the government, which grants or regulates the IH-supplying projects and supports the construction of IH-supplying infrastructure, so that IH-utilizing firms do not have difficulty in using $\mathrm{IH}$. All the three stakeholders wonder how one Gcal of IH supply generates value-added for IH-utilizing firms. For example, an IH-supplying company can use the MV information about IH use to set the price of $\mathrm{IH}$. In other words, to the extent that the production cost of $\mathrm{IH}$ can be recovered, the price of $\mathrm{IH}$ can be set lower than the MV of IH. If the price of IH is lower than the MV of IH, it would be desirable for an IH-utilizing firm to consume IH; otherwise, it would be better for that firm to not consume IH. Moreover, when a public corporation pushes an IH-supplying project, if the associated costs are greater than the MV, the project is economically justified, and government funds can be injected into the project.

The authors think that the framework of the study can be extended in future studies in several ways. First, this study obtained an overall value for the manufacturing industry, but the MV of IH for each sector of the manufacturing industry needs to be investigated by gathering and analyzing more data. This is because the MV of IH for the beverage industry may be significantly different from that for the semiconductor industry. Second, it may be useful to examine how the MV varies as time passes, by conducting the survey for collecting the data for the examination every year for some years and analyzing the collected data. Third, looking into how much the MV changes across the regions and identifying other geographic factors that affect the MV are also good research topics. To the best of the authors' knowledge, there is no research that deals with the marginal value of IH for other countries in the literature. Comparing the findings from this study with those from other studies for foreign countries and analyzing the gap between the two would enable us to obtain a new insight into the MV of IH. These works can provide us with a new point of view concerning the MV of IH.

Author Contributions: All the authors participated in making this article. H.-J.K. proposed the key ideas and quantitatively looked into the data; H.-H.K. conducted a literature review and prepared about half of the paper; and S.-H.Y. made the survey questionnaire and derived the implications of the study results.

Conflicts of Interest: The authors declare no conflict of interest.

\section{References}

1. Javanshir, A.; Sarunac, N.; Razzaghpanah, Z. Thermodynamic analysis of ORC and its application for waste heat recovery. Sustainability 2017, 9, 1974. [CrossRef]

2. Behnaz, R.; Rosen, M.A. District heating and cooling: Review of technology and potential enhancements. Appl. Energy 2012, 93, 2-10.

3. Gebremedhin, A. Optimal utilisation of heat demand in district heating system-A case study. Renew. Sustain. Energy Rev. 2014, 30, 230-236. [CrossRef]

4. Geyer, P.; Delwati, M.; Buchholz, M.; Giampieri, A.; Smallbone, A.; Roskilly, A.P.; Buchholz, R.; Provost, M. Use cases with economics and simulation for thermo-chemical district networks. Sustainability 2018, 10, 599. [CrossRef]

5. Korea Energy Agency. The Handbook of Integrated-Energy Business 2017; Korea Energy Agency: Gyeounggi-do, Korea, 2017.

6. Lim, S.-Y.; Kim, H.-J.; Yoo, S.-H. The demand function for residential heat through district heating system and its consumption benefits in Korea. Energy Policy 2016, 97, 155-160. [CrossRef]

7. Dupont, D.P.; Renzetti, S. The role of water in manufacturing. Environ. Resour. Econ. 2001, 18, 411-432. [CrossRef]

8. Park, S.-Y.; Yoo, S.-H. The economic value of LNG in the Korean manufacturing industry. Energy Policy 2013, 58, 403-407. [CrossRef] 
9. Lim, K.-M.; Yoo, S.-H. Economic value of electricity in the Korean manufacturing industry. Energy Sources Part B Econ. Plan. Policy 2016, 11, 542-546. [CrossRef]

10. Ku, S.-J.; Yoo, S.-H. Economic value of water in the Korean manufacturing industry. Water Resour. Manag. 2012, 26, 81-88. [CrossRef]

11. Wang, H.; Lall, S. Valuing water for Chinese industries: A marginal productivity analysis. Appl. Econ. 2002, 34, 759-765. [CrossRef]

12. Chramcov, B.; Balátě, J. Time series analysis of heat demand. In Proceedings of the 22nd European Conference on Modelling and Simulation, Nicosia, Cyprus, 3-6 June 2008.

13. Christensen, L.; Jorgenson, D.; Lau, L. Transcendental logarithmic production function frontiers. Rev. Econ. Stat. 1973, 55, 29-45. [CrossRef]

14. Ramsey, J.B. Tests for specification errors in classical linear least squares regression analysis. J. R. Stat. Soc. Ser. B 1969, 31, 350-371.

(C) 2018 by the authors. Licensee MDPI, Basel, Switzerland. This article is an open access article distributed under the terms and conditions of the Creative Commons Attribution (CC BY) license (http://creativecommons.org/licenses/by/4.0/). 